recorded from the southern part of the North Sea (including the coasts of England, Holland, and Belgium), the Channel, the Atlantic from the coast of Ireland to Gibraltar, and the whole of the Mediterranean, so that material has been drawn from an area well beyond the strict limits of France.

Prof. Fauvel has himself examined the majority of the species described, and has carefully studied the intricate synonymy, giving effect to the rule of priority so far as he considered this to be desirable in view of the long usage of certain names, and adding under each species a few references to the principal published accounts. The author has redrawn for this publication many figures from well-known memoirs and has added a considerable number of original sketches-the total exceeds 2000 -and with few exceptions these clearly illustrate structural or systematic characters referred to in the text.

A brief introduction is devoted to the consideration of the external morphology-including the chætæof Polychæta, the anatomy of the principal systems of organs, reproduction, general biology, and methods of capture and preservation. The author warns the collector against the use of formalin, and recommends 70 per cent. alcohol as the only suitable preserving fluid.

The Errant Polychæta, with which this volume deals, are subdivided into fifteen families, and a key is given for their separation. Each family is concisely defined, and a key to the sub-families or genera follows. A definition of each genus is given, and, where there is more than one species, a key to these is added. Each species is the subject of a short description, at the end of which are noted the usual habitat of the species and the principal localities from which it has been obtained. The author places the Histriobdellidærepresented by the single genus Histriobdella found in the gill-chamber and on the eggs of the lobsterimmediately after the Eunicidæ, on account of the strong resemblance, recently pointed out by Mesnil and Caullery, of its maxillary apparatus to that of Eunicids.

We hope Prof. Fauvel will be able soon to complete the work by the issue of the second volume, which is to contain the description of the sedentary forms, the Archiannelida, and the Myzostomids.

Marine Products of Commerce. By Dr. Donald K. Tressler (with collaborators). Pp. 762. (New York: The Chemical Catalog Co. Inc., I923.) 9 dollars.

THis book is designed, the author says, for both the scientific and the practical man, and its general treatment indicates that the industrial aspect is that mainly envisaged by the writers. But the work merits a much wider circle of readers, and there are few students of marine zoology but will find it of extraordinary interest. Just as the older text-books of chemistry (such as Roscoe and Schorlemmer) gained enormously in attractiveness by their descriptions of commercial processes, so this book will supply material that has so far been sadly wanting, and will "brighten" the academic study of marine biology. Thus the descriptions of pearls, of the pearling industry, of the utilisation in industry of pearls and pearl shell, of the taking and treatment of the precious red coral, of the manu- facture of "pearl essence" from the scales of fishes, of the ruthless and repulsive industries connected with the capture of whales and seals, are interesting in the extreme, and nowhere else have they been done so well.

In the main, however, the subject-matter of the book is the acquisition and utilisation in industry of products obtained from marine animals and plants. Five chapters deal with obtaining sodium chloride and other salts from sea water and algæ. The extraction and purification of sea salt is very well described, and there are careful accounts of the effects of impurities in the processes of fish preservation. The whole subject of the preservation of fish, crustacea, and molluscs by antiseptics, refrigeration, and canning methods is adequately treated. There are good descriptions of fish and liver oils. A great number of fish conserves and delikatessen, with their mode of preparation, are here described, within the same covers, for the first time. Not only is the treatment of the matter practical, but the scientific interest in all the processes is also kept in the foreground, and good bibliographies, including quite recent work, are given at the end of each chapter. One is impressed with the large amount of research that has been made, in the United States, into industrial processes under the auspices of the Bureau of Fisheries, and with the statement, in the last chapter, of the problems that await attention when Congress sees fit to "appropriate sufficient money to carry out the much-needed investigations" and make full use of the equipment that has apparently been provided. This book is very confidently recommended to practical men as well as to scientific workers engaged on fishery problems.

\section{J. J.}

Assyrian Medical Texts. By R. Campbell Thompson. (Reprinted from the Proceedings of the Royal Society of Medicine, I924, vol. xvi. Section of the History of Medicine.) Pp. 34. (London: John Bale, Sons and Danielsson, Ltd., I924.) 2s. 6d. net.

THE specimens of Assyrian medical texts which $\mathrm{Mr}$. Campbell Thompson has translated are derived from Ashurbanapal's library of clay tablets, which was discovered in 1849 by Sir Austin Henry Layard during excavations at the mound Kouyunjik, near the site of Nineveh. Of the 80,000 fragments of the clay tablets that have found their way to the British Museum, it has been estimated that at least 800 consist of medical texts. The present pamphlet contains texts dealing with diseases of the head and diseases of the eyes only, which clearly illustrate the peculiar features of Assyrian medicine, especially the belief that disease is due to demoniac possession. In consequence of this, incantations and magic rites are interspersed with the remedies, many of which may be traced back to at least 2000 B.C. In some of the texts, incantations and magic rites play the most prominent part, while in others they are only of secondary importance. Although other methods of treatment, such as diet, rest, and massage, were not unknown, the principal part in Assyrian therapeutics was taken by drugs, derived first from plants, trees, and shrubs, of which the roots, twigs, leaves, sap, and seeds were employed; secondly, from mineral substances, including various alkalis and salts; and thirdly, from various stones, which were crushed and used as ingredients in concoctions and 